\title{
Analysis of intervertebral disc degeneration in patients with ossification of the posterior longitudinal ligament
}

\author{
Xi Luo ${ }^{1 \#}$, Kaiqiang Sun ${ }^{1 \#}$, Jian Zhu ${ }^{1 \#}$, Shunmin Wang ${ }^{2 \#}$, Yuan Wang ${ }^{1}$, Jingchuan Sun $^{1}$, Jiangang Shi ${ }^{1}$ \\ ${ }^{1}$ Department of Orthopedics, Changzheng Hospital, The Second Military Medical University, Shanghai, China; ${ }^{2}$ Department of Orthopedics, 910 \\ Hospital, Quanzhou, China
}

Contributions: (I) Conception and design: X Luo, K Sun, J Zhu; (II) Administrative support: Y Wang, J Sun, J Shi; (III) Provision of study materials or patients: Y Wang, J Sun, J Shi; (IV) Collection and assembly of data: X Luo, S Wang; (V) Data analysis and interpretation: X Luo, K Sun; (VI) Manuscript writing: All authors; (VII) Final approval of manuscript: All authors.

"These authors contributed equally to this work.

Correspondence to: Jingchuan Sun; Jiangang Shi. Shanghai Changzheng Hospital, 415 Fengyang Road, Huangpu District, Shanghai, China. Email: sjchxc@foxmail.com; chzhshijg@126.com.

Background: As degenerative disease with nerve compression, little is known about the relationship between cervical ossification of the posterior longitudinal ligament (OPLL) and intervertebral disc degeneration (IVDD). This study investigates the effect of ossification of ligaments on IVDD in patients with cervical OPLL. We focus on the ossification-related segment in patients diagnosed with OPLL, which is characterized by ossification that crosses intervertebral space or occurs concurrently in the upper and lower vertebrae.

Methods: A total of 92 ossification-related segments from 40 patients were involved in the study. X-ray, computed tomography (CT), and magnetic resonance imaging (MRI) were used to evaluate the ossification thickness, disc height, cervical range of motion (ROM) of the segment, Kang's grade, and disc signal loss. We conducted correlation analysis and subgroup comparisons to analyze the type of ossification, ossification thickness, disc height, disc signal loss, ROM and Kang's grade.

Results: The specific ossification thickness was negatively correlated with the disc signal loss $(\mathrm{P}<0.05)$. Specific ossification thickness and specific disc height were positively correlated $(\mathrm{P}<0.05)$. Segments were divided into the nude group (ossification not crossing the intervertebral space) and the covered group (ossification crossing the intervertebral space). The nude group presented smaller ossification thickness and disc height, and a higher grade of disc signal loss and ROM $(\mathrm{P}<0.05)$.

Conclusions: The formation of OPLL may be interrelated with the alleviation of IVDD at the same segment. Furthermore, IVDD is not only related to the limited ROM caused by ossification, but also the size and shape of the ossified mass. A negative correlation exists between the ossification thickness and the severity of IVDD in OPLL patients. Ossification that crosses the interverbal space is associated with lower ROM, a thicker ossified mass, and better disc signal. For patients with nude ossification-related segments, a fusion surgery to restore intervertebral stabilization deserves serious consideration.

Keywords: Ossification of posterior longitudinal ligament (OPLL); degeneration of intervertebral disc; correlation analysis

Submitted Feb 06, 2021. Accepted for publication Nov 10, 2021.

doi: 10.21037/qims-21-154

View this article at: https://dx.doi.org/10.21037/qims-21-154 


\section{Introduction}

Cervical ossification of the posterior longitudinal ligament (OPLL) and intervertebral disc degeneration (IVDD) are common cervical disorders characterized by progressive spinal canal stenosis and the compression of the spinal cord. OPLL and IVDD in patients frequently manifest as hyperreflexia, clumsiness in gait, paresthesia in one or both arms or hands, and radiculopathy signs $(1,2)$. Impairment of motor function caused by neurologic damage can significantly reduce independence and quality of life, requiring prompt surgical intervention.

Patients with both OPLL and IVDD are often encountered in clinical practice. However, few studies have been published that examine the correlation between IVDD and OPLL. Hanakita et al. [1994] suggested that IVDD can promote the growth of OPLL and that the secretion of growth factors by a degenerated disc and mechanical stress imposed on ligaments may be 2 major factors (3). Studies have also shown that cytokines secreted by a degenerated disc can act on ligaments through the paracrine pathway to enhance the osteogenic ability of fibroblasts and to induce the formation of ossification (4). Another mechanism proposed is that the chondrocytes of the fibrous ring of the intervertebral disc could migrate to ligaments and continue to proliferate, causing the ossification of ligaments in the form of cartilaginous ossification (5). Studies related to this hypothesis indicated a latent correlation between the formation of ossification and IVDD at the same segment. However, previous studies have mainly focused on how IVDD promotes ossification. Several other studies have focused on the degeneration of the segments adjacent to ossification or anterior plate, but little attention has been paid to the degenerative characteristics of the discs at the same segments that exhibit OPLL $(6,7)$.

Therefore, our study proposes the concept of the "ossification-related segment", which is characterized by ossification that crosses intervertebral space or occurs concurrently in the upper and lower vertebrae. Our study explored the potential relationship between ossification formation and the severity of IVDD in patients with cervical OPLL. Meanwhile, the non-ossification-related segment adjacent to the ossification-related segment was defined as the "ossification-adjacent segment" to further study the degenerative characteristics of these segments.

\section{Methods}

\section{Patients' population}

We retrospectively reviewed the preoperative $\mathrm{X}$-ray (neutral and flexion-extension view), computed tomography (CT), and magnetic resonance imaging (MRI; supine position with natural extension of the cervical spine) images of 40 patients who underwent surgical decompression in our hospital from January 2018 to December 2019 due to cervical OPLL. The demographic data including age, gender, ossified segments, type of ossification, and duration of symptoms were recorded. All patients received a surgical operation to release the neural elements before this study.

Patients were enrolled if they satisfied the following criteria: (I) the patient exhibited cervical OPLL that was confirmed by CT, and (II) the patient had complete medical records.

Patients were excluded if they had any of the following: (I) previous history of cervical spine surgery; (II) cervical trauma, infection, or tumor; and (III) idiopathic, congenital, or other disease-associated deformity in the cervical spine. The study was conducted in accordance with the Declaration of Helsinki (as revised in 2013). This singlecenter retrospective study was approved by the institution review board of Changzheng Hospital. Informed consent was obtained from all individual participants included in the study.

\section{Radiological evaluation}

Three spine surgeons with more than 5 years of working experience measured the imaging data of ossificationrelated segments. Each data point was measured three times, from which the average was calculated and recorded. The following measurement indexes were used:

(I) X-ray lateral radiograph;

(i) Range of motion (ROM) of corresponding segment: the angle between the upper and lower endplates of the intervertebral space in hyperextension and hyperflexion position was measured at each ossification-related segment. The difference between the 2 angles was considered to be the ROM of the segment. 
Table 1 Demographic data

\begin{tabular}{lc}
\hline Information & Overall $(\mathrm{n}=40)$ \\
\hline Gender & 23 \\
Female & 17 \\
Male & $49.0 \pm 8.3$ \\
Age (year) & \\
Ossification type & 7 \\
Localized & 16 \\
Segmental & 5 \\
Continuous & 12 \\
Mixed & $3.2 \pm 1.1$ \\
Average ossified segments & $18.3 \pm 7.1$ \\
Duration of symptoms (month)
\end{tabular}

Values are presented as mean \pm SD.

(II) CT midsagittal plane;

(i) Transverse diameter of vertebra: the midsagittal diameter (the distance between the midpoints of anterior and posterior edges of vertebra) of the upper and lower vertebrae of the ossification-related segment was measured.

(ii) Disc height: the distance between the midpoint of the lower edge of the upper vertebra and the midpoint of the upper edge of the lower vertebra was measured.

(iii) Thickness of ossification at each level: the thickness of the thickest part of the ossified mass of the upper and lower vertebrae was measured, and the mean value of the 2 measurements was calculated.

To correct the differences of the indexes among individuals during correlation analysis, specific ossification thickness and specific disc height were introduced. These were defined as the quotient of ossification thickness and disc height with the mean value of the sagittal diameter of the upper and lower vertebrae in the corresponding intervertebral space.

(III) T2-weighted MRI;

Disc signal loss is evaluated with reference to the Pfirrmann grading system (8). Each grade has the following characteristics: grade I, bright hyperintense white signal intensity; grade II, hyperintense white signal with a horizontal gray band; grade III, intermittent gray signal intensity with the distinction between the nucleus and annulus being unclear; grade IV, intermittent gray and black signal intensity with the distinction between the nucleus and annulus being lost; and grade $\mathrm{V}$, black signal intensity with the distinction between the nucleus and annulus being lost.

Kang's MRI grading system was used to assess the degree of cervical spinal cord compression at each level with the following criteria: grade 0 , no spinal canal stenosis; grade 1, subarachnoid compression exceeding $50 \%$; grade 2, spinal cord compression causing deformity; and grade 3 , spinal cord T2-weighted signal changes (9).

According to the presence of the ossification crossing the intervertebral space, the ossificationrelated segments were further divided into 2 groups: the nude group (intervertebral space is not involved by ossification) and the covered group (ossification is observed at the intervertebral space level). Data were analyzed for each subgroup.

\section{Statistical analysis}

Statistical analysis was conducted with SPSS 22.0 (IBM Corp, Armonk, NY, USA). The data are presented as the mean \pm standard deviation. The difference in the quantitative data between groups was tested by a 2 -sample independent $t$-test, and the difference of the analysis of variance and pairwise comparisons were determined by the least significant difference (LSD) test. Pearson correlation analysis was used for quantitative data, while Spearman correlation analysis was used for grade data. $\mathrm{P}$ values less than 0.05 were considered to be statistically significant.

\section{Results}

A total of 92 ossification-related segments were obtained from 40 patients (23 males, 17 females; average age $49.0 \pm 8.3$ years; Table 1$)$.

Our analysis showed a correlation between the morphology of ossification and the degree of IVDD at the corresponding level. Correlation analysis suggested a negative correlation of specific ossification thickness with disc signal loss $(\mathrm{r}=-0.443 ; \mathrm{P}<0.05)$ and a positive correlation with specific disc height $(\mathrm{r}=0.322 ; \mathrm{P}<0.05)$. However, ROM and Kang's grade had no significant correlation 

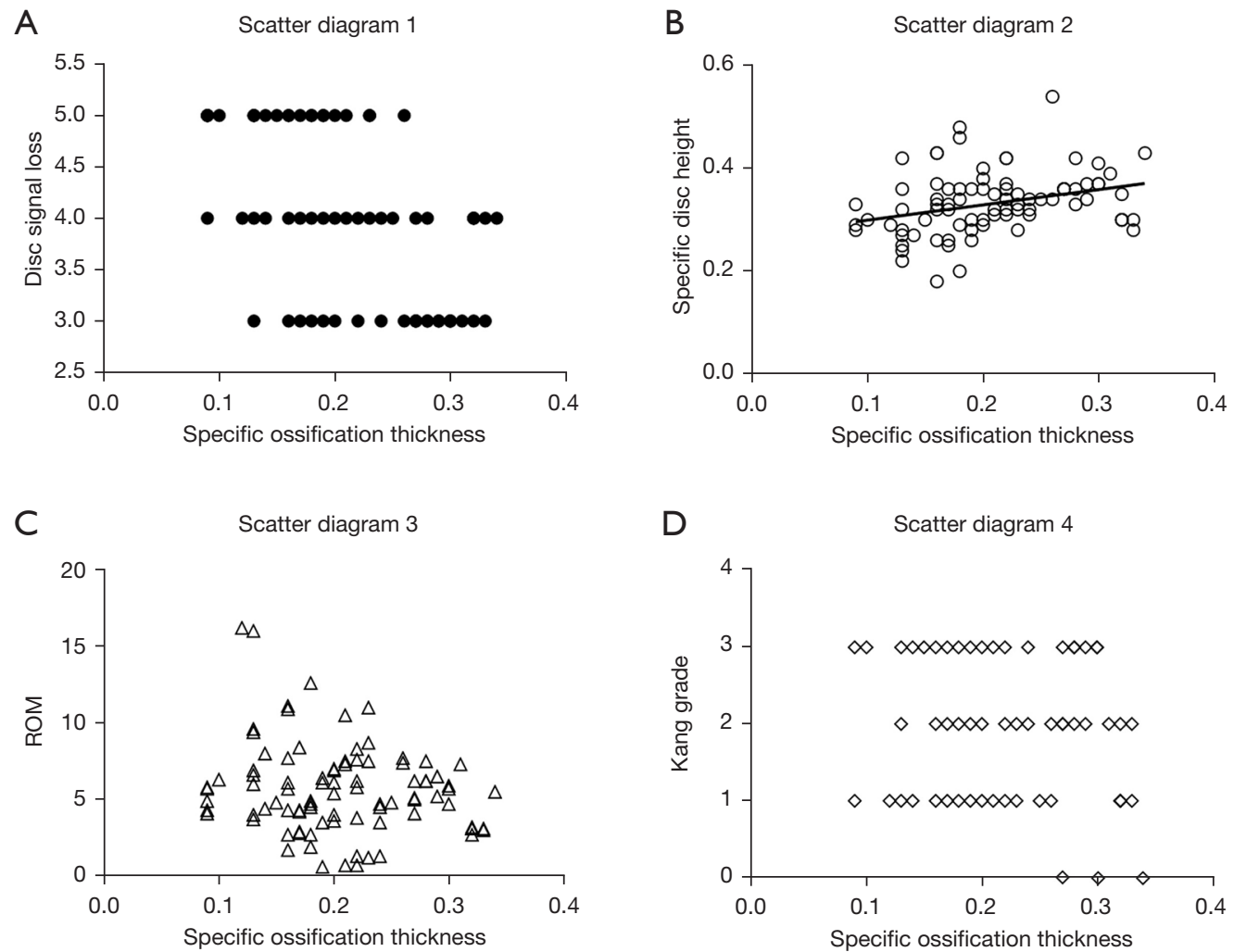

Figure 1 Correlation between ossification and IVDD. (A) Specific ossification thickness was negatively correlated with disc signal loss. (B) Specific ossification thickness was positively correlated with specific disc height. (C,D) Specific ossification thickness showed no correlation between ROM or Kang's grade. IVDD, intervertebral disc degeneration; ROM, range of motion.

with specific ossification thickness (both $\mathrm{P}>0.05$; Figure 1). Simultaneously, ROM displayed no significant correlation with disc signal loss or disc height.

According to the morphology of ossification, the ossification-related segments can be divided into 4 types: segmental type, stalagmite type, beak type, and continuous type (Figure 2). Among them, only the intervertebral space of the segmental type is not involved in ossification. Therefore, 92 ossification-related segments were further divided into the nude group (which only included the segmental type, $n=40$ ) and the covered group (which included the stalagmite type, beak type, and continuous type, $\mathrm{n}=52)$. Compared with the nude group, the covered group had a relatively lower $\mathrm{ROM}(\mathrm{P}<0.05)$, with a thicker ossified mass $(\mathrm{P}<0.05)$, larger disc height, brighter disc signal $(\mathrm{P}<0.05)$, and similar Kang's grade $(\mathrm{P}>0.05$; Table 2$)$.

A total of 52 ossification-adjacent segments were further observed. Compared with the ossification-related segments, the ossification-adjacent segments showed milder IVDD and spinal cord compression (better disc signal, higher specific disc height, and lower Kang's grade, $\mathrm{P}<0.05$; Table 3). Depending on whether it was adjacent to either the covered segment or the nude segment, the 52 ossification-adjacent segments were divided into 24 covered-adjacent segments and 28 nude-adjacent segments. There was no significant difference between the 2 subgroups $(\mathrm{P}>0.05$; Table 4$)$.

\section{Discussion}

Our study found that, in OPLL patients, the thickness of the ossified mass was significantly related to the degree of IVDD at the corresponding level. Thicker ossification correlated smaller disc height loss and darker disc signal. However, we did not observe significant correlations between ROM and disc signal loss, disc height, and thickness of the ossified mass. The results suggest that the existence of ossification may play a protective role in delaying the progress of IVDD at the corresponding level. The potential static support produced by ossification may function to maintain the intervertebral height. However, 
A

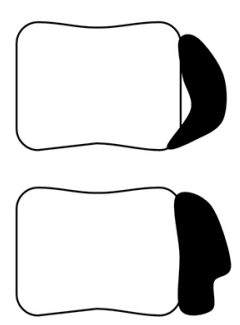

B

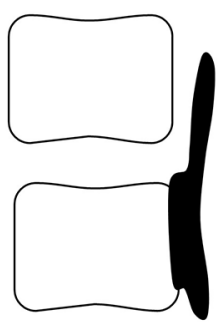

C

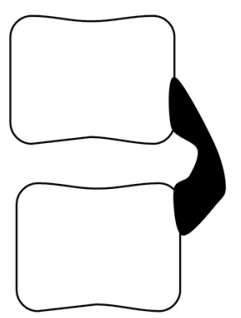

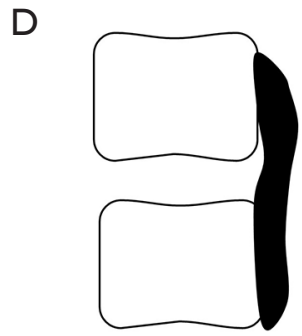

Figure 2 Four types of ossification-related segments. Four types of ossification-related segments were observed. (A) Segmental type: the ossified masses were located at the upper and lower sides of the intervertebral space, but did not cross the intervertebral space. (B) Stalagmite type: the ossified masses extended from the base of the ossification across the intervertebral space but did not fuse with the vertebra across the intervertebral space. (C) Beak type: the ossified masses of the upper corner of lower vertebra and the lower corner of upper vertebra fused at the intervertebral space. (D) Continuous type: the ossified masses bridged the upper and lower vertebrae and completely fused.

Table 2 Subgroup comparison of ossification-related segments

\begin{tabular}{|c|c|c|c|}
\hline Measurement & Covered $(n=40)$ & Nude $(n=52)$ & $P$ \\
\hline Ossification thickness & $4.42 \pm 1.19$ & $3.17 \pm 0.95$ & $<0.001^{*}$ \\
\hline Disc signal loss & $3.73 \pm 0.75$ & $4.08 \pm 0.71$ & $<0.05^{\star}$ \\
\hline ROM & $3.78 \pm 2.00$ & $6.89 \pm 2.90$ & $<0.001^{*}$ \\
\hline Specific ossification thickness & $0.24 \pm 0.06$ & $0.18 \pm 0.52$ & $<0.05^{\star}$ \\
\hline Kang's grade & $1.92 \pm 0.74$ & $2.10 \pm 0.98$ & $>0.05$ \\
\hline
\end{tabular}

Values are presented as mean $\pm \mathrm{SD} .{ }^{*}$, statistically significant. ROM, range of motion.

Table 3 Comparison between ossification-related and ossification-adjacent segments

\begin{tabular}{lccc}
\hline Measurement & Ossification-related $(\mathrm{n}=92)$ & Ossification-adjacent $(\mathrm{n}=52)$ & $\mathrm{P}$ \\
\hline Disc height & $6.00 \pm 1.39$ & $6.03 \pm 1.26$ & $>0.05$ \\
Disc signal loss & $3.92 \pm 0.74$ & $3.40 \pm 0.60$ & $<0.001^{\star}$ \\
Specific disc height & $0.33 \pm 0.06$ & $0.36 \pm 0.07$ & $<0.05^{\star}$ \\
ROM & $5.54 \pm 2.97$ & $6.33 \pm 3.17$ & $>0.05$ \\
Kang's grade & $2.00 \pm 0.85$ & $1.31 \pm 0.92$ & $<0.001^{\star}$
\end{tabular}

Values are presented as mean \pm SD. *, statistically significant. ROM, range of motion.

the protective effect cannot be entirely attributed to the change in ROM caused by ossification.

Static and dynamic pressures are important catalysts that accelerate IVDD. Clinical and biomechanical studies have shown that the increase of pressure within a disc can lead to degeneration (10). Under continuous pressure, the transport of oxygen, nutrition, and metabolites in the intervertebral disc can be blocked, resulting in apoptosis of nucleus pulposus cells and degeneration $(11,12)$. In a degenerated disc, the content of collagen fibers decreases, the annulus of fibers is relaxed, and the nucleus pulposus degenerates from being a nearly incompressible fluid into a gelatinous substance. Therefore, the loss of height of a degenerated disc may occur under a longitudinal compressive load (13). 
Table 4 Subgroup comparison of ossification-adjacent segments

\begin{tabular}{lccc}
\hline Measurement & Covered-adjacent $(\mathrm{n}=24)$ & Nude-adjacent $(\mathrm{n}=28)$ & $\mathrm{P}$ \\
\hline Disc height & $5.75 \pm 1.29$ & $6.28 \pm 1.21$ & $>0.05$ \\
Disc signal loss & $3.46 \pm 0.67$ & $3.36 \pm 0.56$ & $>0.05$ \\
ROM & $5.71 \pm 3.31$ & $6.86 \pm 3.00$ & $>0.05$ \\
Specific disc height & $0.36 \pm 0.63$ & $0.37 \pm 0.80$ & $>0.05$ \\
Kang's grade & $1.33 \pm 0.96$ & $1.28 \pm 0.90$ & $>0.05$ \\
\hline
\end{tabular}

Values are presented as mean $\pm \mathrm{SD} .{ }^{*}$, statistically significant. ROM, range of motion.

Accordingly, in clinical practice, interspinous implants are used to support the intervertebral space, reduce the load of the intervertebral disc, and alleviate IVDD $(14,15)$.

The posterior longitudinal ligament (PLL) is the most rigid structure in cervical ligaments, and the change of its material properties due to ossification can significantly affect the distribution of loads on surrounding structures (16-18). The metaplasia from fibrous tissue to cartilage during ossification causes the fibers responsible for ligament transform to form a frame structure similar to bone trabeculae, which gradually increases the stiffness of the PLL (19). The ligament, which can only bear tensile stress, also has a bearing capacity for compressive stress after ossification, so it can share part of the load of the anterior column of the cervical spine. Previous studies using finite element analysis have shown that, after the PLL hardens (at which time the Young's modulus increases, and the material property changes from tensile and noncompressive to tensile and compressive), the stress of the vertebrae and the intervertebral disc decreases, the stress concentration of the PLL increases, and the load borne by the PLL significantly increases compared with that before hardening (20). Previous reports have also proposed that the secondary changes, such as osteophyte formation and calcification of the ligament after IVDD, might recover the stabilization of the spine (21). Based on the results of our study, which showed a negative correlation between ossification thickness and IVDD, the ossified PLL may help to support the intervertebral space and enhance the adaptability to pressure of the ossified segment, which can alleviate the IVDD at the corresponding level.

The results of subgroup analysis demonstrated that, compared with the nude group, the covered group exhibited a smaller ROM, larger ossification thickness, better disc signal, and higher disc height $(\mathrm{P}<0.05)$. Anatomically, the PLL lies along the full length of the anterior wall of the cervical canal, but the development of OPLL is not synchronous. The initial point of ossification is generally at the vertebral level. The ossification gradually progresses to the deep part of the ligament and spreads to the cranial and caudal ends. At the intervertebral level, the ossification progress is relatively slow. Invading new segments and bridging osteogenesis are both important forms of the ossification progress (22). In our study, the ossified mass in the covered group showed more mature characteristics of ossification, which not only increased significantly in thickness, but also had a more closely related spatial relationship to the intervertebral disc. Therefore, the ossification that crossed intervertebral space might have reduced the static pressure and limited the dynamic factors, so the IVDD in the covered group was less severe than that in the nude group.

According to Kang's grading system, there was no significant difference in spinal cord compression between the covered and nude groups. Previous research has suggested that, in OPLL patients, spinal cord compression caused by intervertebral disc herniation cannot be ignored (23). In the process of ossification, non-ossified sites were more prone to significant instability and aggravation of spinal cord injury (24). The dynamic factor caused by cervical instability was closely related to the incidence of myelopathy in OPLL patients and that the application of simple fusion without decompression to eliminate the dynamic effect could also achieve satisfactory results (25). This was consistent with the high ROM found in the nude group in our study. Therefore, in theory, for patients with nude ossification-related segments, it may be more helpful to achieve decompression by strengthening the intervertebral stabilization and eliminating the dynamic effect through fusion surgery.

Previous research has suggested a potential correlation between ROM and ossification. In patients with cervical OPLL but without symptoms of myelopathy, as the OPLL occupation ratio increased, the segmental ROM decreased, 
suggesting that excessive ROM played a key role in the development of myelopathy in patients with cervical OPLL (26). A previous research among asymptomatic volunteers showed a negative correlation between ROM and the severity of IVDD at levels involving ossification (27). However, in our study, ROM displayed no significant correlation with ossification thickness, disc signal loss, or disc height. This may be caused by the continuous change of ROM as ossification develops. On the one hand, a high ROM can stimulate the development of OPLL $(28,29)$. A ROM greater than $5^{\circ}$ and non-bridged ossification across the intervertebral space were regarded as risk factors for the development of ossification (30). In segments with high motional frequency and a small amount of stiffness, the stress of the spinal ligament was more complex, which might be related to the progress of ossification $(12,30)$. On the other hand, ROM tends to decrease at ossified segments. Our subgroup analysis showed that the ROM of the covered group was significantly smaller than that of the nude group, suggesting that ossification might occur in stabilizing segments. Previous studies have found that the formation of continuous ossification could significantly reduce $\mathrm{ROM}$ and that the connection between the ossified mass and vertebrae, and the formation of bone trabeculae inside the ossified mass, were signs of stabilization of the ossified segment $(31,32)$. Past study reported ossification that involved but did not cross the disc space to be a risk factor for the progress of ossification, but did not conclude that complete bridging ossification was a risk factor (33).

Previous studies have shown that the ossificationadjacent segments are similar to the adjacent segments after undergoing fusion, and both present the characteristics of stress concentration, which may lead to the acceleration of IVDD. A total of 52 ossification-adjacent segments were observed in this study. Because C5/6 and C4/5 are the segments that most frequently develop IVDD and OPLL (34), the ossification-adjacent segments were naturally distributed in the non-prone segments of IVDD: C2/3 (4, 7.7\%), C3/4 (12, 23.1\%), C4/5 (12, 23.1\%), C5/6 (0, 0\%), C6/ 7 (16, 30.8\%), and C7/T1 (8, 15.4\%). Generally, the degree of IVDD and spinal cord compression of ossification-adjacent segments were significantly less than that of ossification-related segments $(\mathrm{P}<0.05)$. Our results indicated that the effect of ossification on ossification-adjacent segments is limited. Considering that the ROM of the covered segment was significantly lower than that of the nude segment, we performed a subgroup analysis, which showed no significant difference in the parameters between the covered-adjacent segments and nude-adjacent segments $(\mathrm{P}>0.05)$. We have two possible explanations for this phenomenon. First, the degeneration of ossification-adjacent segments is different from that of adjacent segments after undergoing fusion. Although the ROM of ossification-related segments (especially covered segment) decreased, the intervertebral space was still not completely fused, so the influence on ossification-adjacent segments was limited (35). Second, regarding adjacent segments after fusion, fusion surgery is an initial factor that contributes to degeneration of adjacent segments, and there is a clear sequence of events and an explicit causal relationship. However, the degeneration of ossificationadjacent segments is formed by long-term interaction between ossification and IVDD, and so prospective followup evidence is necessary to clarify the effect of ossification on ossification-adjacent segments.

There is a significant correlation between IVDD and aging. IVDD begins gradually from adulthood in a healthy population. Aging was once believed as the only independent variable that was significantly related to the development of spondylotic changes (36). In our study, we noted the average age according to the loss of disc signal in all patients, which was 59.25 years old for grade $\mathrm{V}$ patients, 47.02 years for grade IV patients, and 42.81 years for grade III patients. This shows a trend in which IVDD increases with age. This finding is also applicable to the progress of ossification, and the potential influence of IVDD and ossification is likely to be a long-term process. Although ossification of spinal ligaments may be influenced by underlying genetics, its manifestation at older ages suggests an age-related pathogenesis. From the perspective of gene background, according to the potential for ossification formation, OPLL patients could be divided into the following types: pure type (without obvious disc herniation) and superimposed type (with obvious disc herniation). Patients in the pure type can develop ossification in the early years, with evident ossification and slight IVDD, while patients in the superimposed type have weak potential of ossification formation, with delayed and mild ossification and severe IVDD (37). This view is consistent with the findings of our study, suggesting that the progress of ossification can affect the degree of IVDD. The frequent manifestation of OPLL without signs of degenerative disc disease supports additional biomechanical processes in IVDD. The progression of OPLL occurred more frequently at the levels of total disc replacement than at those of fusion, suggesting that the growth of the 
ossified mass can occur without the influence of IVDD (38). In contrast, other researchers suggest prolapse of the nucleus pulposus to be an initiating stimulus for OPLL (39). However, to confirm the causal relationship between IVDD and ossification, it is necessary to carry out long-term follow-up studies to dynamically observe the cervical spines of a young population.

The main limitations of this study are as follows. First, we used a cross-sectional study, from which it was difficult to determine the sequence of events in IVDD and ossification growth. Considering the long-term natural history of OPLL, a cohort study with frequent observation periods and adequate cases may be needed to verify our findings. Second, axial rotation was not considered regarding the motion of each segment. Because of this limitation, the influence between ossification and threedimensional motion has not been fully discussed. A CT imaging research on head-turning posture should be carried out to further clarify this matter. Finally, because of the choice of surgical method, the ossified ligaments of all patients were not directly resected, so the ossification specimens could not be obtained. In order to verify the supporting effect of ossification, it is necessary to measure the internal pressure of the intervertebral disc and use a histological section for further observation of ossification in the future.

\section{Conclusions}

We found a significant correlation between the degree of ossification and the IVDD in OPLL patients. As ossification thickness increased, the IVDD at corresponding levels was alleviated, which was indicated by the brightening of disc signal and the increase of disc height. At the same time, compared with the nude group, the covered group had smaller ROM, larger ossification thickness, and better disc signal. This shows that the segments with ossification that crossed the interverbal space were characterized by a smaller ROM and less IVDD. Therefore, the formation of OPLL may play a crucial role in slowing down IVDD at the corresponding levels. For patients with nude ossificationrelated segments, which show more significant IVDD, a fusion surgery to eliminate the effect of instability deserves serious consideration.

\section{Acknowledgments}

Funding: None.

\section{Footnote}

Conflicts of Interest: All authors have completed the ICMJE uniform disclosure form (available at https://dx.doi. org/10.21037/qims-21-154). The authors have no conflicts of interest to declare.

Ethical Statement: The authors are accountable for all aspects of the work in ensuring that questions related to the accuracy or integrity of any part of the work are appropriately investigated and resolved. The study was conducted in accordance with the Declaration of Helsinki (as revised in 2013). This single-center retrospective study was approved by the institution review board of Changzheng Hospital. Informed consent was obtained from all individual participants included in the study.

Open Access Statement: This is an Open Access article distributed in accordance with the Creative Commons Attribution-NonCommercial-NoDerivs 4.0 International License (CC BY-NC-ND 4.0), which permits the noncommercial replication and distribution of the article with the strict proviso that no changes or edits are made and the original work is properly cited (including links to both the formal publication through the relevant DOI and the license). See: https://creativecommons.org/licenses/by-nc-nd/4.0/.

\section{References}

1. Fujimori T, Iwasaki M, Okuda S, Takenaka S, Kashii M, Kaito T, Yoshikawa H. Long-term results of cervical myelopathy due to ossification of the posterior longitudinal ligament with an occupying ratio of $60 \%$ or more. Spine (Phila Pa 1976) 2014;39:58-67.

2. Toledano M, Bartleson JD. Cervical spondylotic myelopathy. Neurol Clin 2013;31:287-305.

3. Hanakita J, Suwa H, Namura S, Mizuno M, Ootsuka T, Asahi M. The significance of the cervical soft disc herniation in the ossification of the posterior longitudinal ligament. Spine (Phila Pa 1976) 1994;19:412-8.

4. Kang YM, Suk KS, Lee BH, Kim HS, Lee KI, Park SY, Lee HM, Moon SH. Herniated intervertebral disk induces hypertrophy and ossification of ligamentum flavum. J Spinal Disord Tech 2014;27:382-9.

5. Furusawa N, Baba H, Imura S, Fukuda M. Characteristics and mechanism of the ossification of posterior longitudinal ligament in the tip-toe walking Yoshimura (twy) mouse. Eur J Histochem 1996;40:199-210. 
6. Yang JY, Song HS, Lee M, Bohlman HH, Riew KD. Adjacent level ossification development after anterior cervical fusion without plate fixation. Spine (Phila Pa 1976) 2009;34:30-3.

7. Lee CH, Sohn MJ, Lee CH, Choi CY, Han SR, Choi BW. Are There Differences in the Progression of Ossification of the Posterior Longitudinal Ligament Following Laminoplasty Versus Fusion?: A Meta-Analysis. Spine (Phila Pa 1976) 2017;42:887-94.

8. Pfirrmann CW, Metzdorf A, Zanetti M, Hodler J, Boos N. Magnetic resonance classification of lumbar intervertebral disc degeneration. Spine (Phila Pa 1976) 2001;26:1873-8.

9. Kang Y, Lee JW, Koh YH, Hur S, Kim SJ, Chai JW, Kang HS. New MRI grading system for the cervical canal stenosis. AJR Am J Roentgenol 2011;197:W134-40.

10. Adams MA, Roughley PJ. What is intervertebral disc degeneration, and what causes it? Spine (Phila Pa 1976) 2006;31:2151-61

11. Wang SZ, Rui YF, Lu J, Wang C. Cell and molecular biology of intervertebral disc degeneration: current understanding and implications for potential therapeutic strategies. Cell Prolif 2014;47:381-90.

12. Gantenbein B, Illien-Jünger S, Chan SC, Walser J, Haglund L, Ferguson SJ, Iatridis JC, Grad S. Organ culture bioreactors--platforms to study human intervertebral disc degeneration and regenerative therapy. Curr Stem Cell Res Ther 2015;10:339-52.

13. Lu YM, Hutton WC, Gharpuray VM. Can variations in intervertebral disc height affect the mechanical function of the disc? Spine (Phila Pa 1976) 1996;21:2208-16; discussion 2217.

14. Yao QQ, Zheng SN, Cheng L, Yuan P, Zhang DS, Liao XW, Xu Y, Wang LM. Effects of a new shape-memory alloy interspinous process device on pressure distribution of the intervertebral disc and zygapophyseal joints in vitro. Orthop Surg 2010;2:38-45.

15. Swanson KE, Lindsey DP, Hsu KY, Zucherman JF, Yerby SA. The effects of an interspinous implant on intervertebral disc pressures. Spine (Phila Pa 1976) 2003;28:26-32.

16. Keller TS. Predicting the compressive mechanical behavior of bone. J Biomech 1994;27:1159-68.

17. Zhong ZC, Wei SH, Wang JP, Feng CK, Chen CS, Yu $\mathrm{CH}$. Finite element analysis of the lumbar spine with a new cage using a topology optimization method. Med Eng Phys 2006;28:90-8.

18. Yoganandan N, Kumaresan SC, Voo L, Pintar FA, Larson SJ. Finite element modeling of the C4-C6 cervical spine unit. Med Eng Phys 1996;18:569-74.

19. Motegi H, Yamazaki M, Goto S, Mikata A, Moriya H. Proliferating cell nuclear antigen in hypertrophied spinal ligaments. Immunohistochemical localization of proliferating cell nuclear antigen in hypertrophied posterior longitudinal ligament of the cervical spine. Spine (Phila Pa 1976) 1998;23:305-10.

20. Niu L, Li N, Liu Y, Wang W. Biomechanics influence in ossification of the posterior longitudinal ligament: a finite element model of cervical spine. Beijing Biomedical Engineering 2018;37:11.

21. Stokes IA, Wilder DG, Frymoyer JW, Pope MH. 1980 Volvo award in clinical sciences. Assessment of patients with low-back pain by biplanar radiographic measurement of intervertebral motion. Spine (Phila Pa 1976) 1981;6:233-40.

22. Nakamura H. A radiographic study of the progression of ossification of the cervical posterior longitudinal ligament: the correlation between the ossification of the posterior longitudinal ligament and that of the anterior longitudinal ligament. Nihon Seikeigeka Gakkai Zasshi 1994;68:725-36.

23. Wang XR, Kwok TCY, Griffith JF, Man Yu BW, Leung JCS, Wáng YXJ. Prevalence of cervical spine degenerative changes in elderly population and its weak association with aging, neck pain, and osteoporosis. Ann Transl Med 2019;7:486.

24. Matsunaga S, Sakou T, Arishima Y, Koga H, Hayashi K, Komiya S. Quality of life in elderly patients with ossification of the posterior longitudinal ligament. Spine (Phila Pa 1976) 2001;26:494-8.

25. Onari K, Akiyama N, Kondo S, Toguchi A, Mihara H, Tsuchiya T. Long-term follow-up results of anterior interbody fusion applied for cervical myelopathy due to ossification of the posterior longitudinal ligament. Spine (Phila Pa 1976) 2001;26:488-93.

26. Fujiyoshi T, Yamazaki M, Okawa A, Kawabe J, Hayashi K, Endo T, Furuya T, Koda M, Takahashi K. Static versus dynamic factors for the development of myelopathy in patients with cervical ossification of the posterior longitudinal ligament. J Clin Neurosci 2010;17:320-4.

27. Liu B, Wu B, Van Hoof T, Okito JP, Liu Z, Zeng Z. Are the standard parameters of cervical spine alignment and range of motion related to age, sex, and cervical disc degeneration? J Neurosurg Spine 2015;23:274-9.

28. Matsunaga S, Sakou T, Taketomi E, Nakanisi K. Effects of strain distribution in the intervertebral discs on the progression of ossification of the posterior longitudinal 
ligaments. Spine (Phila Pa 1976) 1996;21:184-9.

29. Chen Y, Chen D, Wang X, Yang H, Liu X, Miao J, Yu F. Significance of segmental instability in cervical ossification of the posterior longitudinal ligament and treated by a posterior hybrid technique. Arch Orthop Trauma Surg 2013;133:171-7.

30. Park S, Lee DH, Ahn J, Cho JH, Lee SK, Kim KJ, Park JH, Hwang CJ, Park JW, Lee CS. How Does Ossification of Posterior Longitudinal Ligament Progress in Conservatively Managed Patients? Spine (Phila Pa 1976) 2020;45:234-43.

31. Ito K, Yukawa Y, Machino M, Kobayakawa A, Kato F. Range of motion determined by multidetector-row computed tomography in patients with cervical ossification of the posterior longitudinal ligament. Nagoya J Med Sci 2015;77:221-8.

32. Choi BW, Baek DH, Sheffler LC, Chang H. Analysis of progression of cervical OPLL using computerized tomography: typical sign of maturation of OPLL mass. J Neurosurg Spine 2015;23:539-43.

33. Lee DH, Cho JH, Kim NH, Kim S, Choi J, Hwang CJ, Lee CS. Radiological risk factors for progression of ossification of posterior longitudinal ligament following laminoplasty. Spine J 2018;18:1116-21.

Cite this article as: Luo X, Sun K, Zhu J, Wang S, Wang Y, Sun J, Shi J. Analysis of intervertebral disc degeneration in patients with ossification of the posterior longitudinal ligament. Quant Imaging Med Surg 2022;12(3):1919-1928. doi: 10.21037/ qims-21-154
34. Peng B, DePalma MJ. Cervical disc degeneration and neck pain. J Pain Res 2018;11:2853-7.

35. Cunningham BW, Gordon JD, Dmitriev AE, Hu N, McAfee PC. Biomechanical evaluation of total disc replacement arthroplasty: an in vitro human cadaveric model. Spine (Phila Pa 1976) 2003;28:S110-7.

36. Rudy IS, Poulos A, Owen L, Batters A, Kieliszek K, Willox J, Jenkins H. The correlation of radiographic findings and patient symptomatology in cervical degenerative joint disease: a cross-sectional study. Chiropr Man Therap 2015;23:9.

37. Lee JK, Ham CH, Kwon WK, Moon HJ, Kim JH, Park YK. A New Classification for Cervical Ossification of the Posterior Longitudinal Ligament Based on the Coexistence of Segmental Disc Degeneration. J Korean Neurosurg Soc 2021;64:69-77.

38. Ham JS, Kim JH, Yoon JH, Hwang SH, Yoon SH. Progression of Ossification of the Posterior Longitudinal Ligament after Cervical Total Disc Replacement. Korean J Neurotrauma 2019;15:135-42.

39. Inamasu J, Guiot BH, Sachs DC. Ossification of the posterior longitudinal ligament: an update on its biology, epidemiology, and natural history. Neurosurgery 2006;58:1027-39; discussion 1027-39. 